\title{
Children screening positive for language delay at 2.5 years: language disorder and developmental profiles
}

This article was published in the following Dove Press journal:

Neuropsychiatric Disease and Treatment

\author{
Ulrika Schachinger- \\ Lorentzon' \\ Björn Kadesjö ${ }^{2}$ \\ Christopher Gillberg ${ }^{2}$ \\ Carmela Miniscalco ${ }^{1,2}$ \\ 'Department of Pediatric Speech and \\ Language Pathology, Queen Silvia \\ Children's Hospital, Gothenburg, \\ Sweden; ${ }^{2}$ Gillberg Neuropsychiatry \\ Centre, Institute of Neuroscience and \\ Physiology, University of Gothenburg, \\ Gothenburg, Sweden
}

Correspondence: Ulrika SchachingerLorentzon

Department of Pediatric Speech and Language Pathology, Queen Silvia Children's Hospital, Sahlgrenska University Hospital, Folkungagatan 16 , 4II 02 Gothenburg, Sweden Tel +46 31 3426185

Email ulrika.s.lorentzon@vgregion.se
Purpose: To characterize language disorder and developmental profiles in children who screened positive for language delay but negative for autism at 2.5 years of age.

Patients and methods: The first 100 children who screened positive for language delay - but negative for autism - in 2016 were assessed in detail by speech language pathologists. Parents completed a newly developed questionnaire covering eight domains - Motor, Executive functions, Perception, Memory, Language, Learning, Social skills and Child's behaviour - with impairment scored for each domain.

Results: ICD-10 language disorder diagnoses were made in 87/100 children ( 29 girls, 58 boys). Of 52 children with mixed receptive-expressive language disorder, $32 \%$ had problems in other developmental areas according to the "global rating" in the impairment questions of the questionnaire. Of the 35 with expressive language disorder, $21 \%$ had problems in other areas according to the impairment questions. Thirteen children had isolated language delay with no other diagnoses according to the speech and language pathologists' assessment; however, 23\% of them had problems according to the parental rating on the impairment questions.

Conclusion: Most children screening positive for language delay but negative for autism at age 2.5 years were diagnosed with ICD-10 language disorder diagnoses. Parents in about one in four cases reported impairing problems within other developmental areas. Possible explanations for the findings are discussed.

Keywords: comorbidity, language disorder, neurodevelopmental, parental questionnaire, preschool children

\section{Introduction}

Language is an important human skill, influenced by both genetic and environmental factors and socioeconomic status. ${ }^{1}$ Therefore, if a child exhibits problems with language development, the "cause" is now often considered to be multifactorial. ${ }^{2}$ Clinicians urgently need some way to distinguish between children presenting with early language delays who are likely to grow out of their problems and those who are likely to have persisting problems. ${ }^{3,4}$

Developmental language disorder (DLD) is a new concept that been proposed by Reilly et $\mathrm{al}^{5}$ and Ebbels et $\mathrm{al}^{6}$ corresponding to the definition of specific developmental disorders of speech and language in the ICD-10. ${ }^{7}$ Bishop et al ${ }^{8,9}$ recently carried out a large consensus work (CATALISE) involving researchers and speech and language pathologists (SLPs) from the English speaking world so as to correctly describe criteria and terminology when identifying children with language impairment. It was agreed that the term "language disorder" should be used if the child has a profile of language 
difficulties that causes functional impairment in everyday life and is associated with poor prognosis. DLD should be used when the language disorder is not associated with a known biomedical etiology. It was also agreed that: 1) presence of risk factors (neurobiological or environmental) does not preclude a diagnosis of DLD; 2) DLD can co-occur with other neurodevelopmental disorders (eg, ADHD); and 3) DLD does not require a mismatch between verbal and nonverbal ability. The Catalise consortium also stated that some children need language interventions because they have a different mother tongue than the language spoken in the surrounding community and have been exposed to and used the majority language too little to master it. These children do not have language disorder or DLD, unless there is evidence that they have the same difficulties in all their languages. ${ }^{8,9}$

DLD often occurs in the context of other developmental/ neurodevelopmental difficulties, including attention problemsADHD,${ }^{10}$ motor difficulties - DCD, reading difficulties, ${ }^{12}$ behavioral problems, social difficulties and autism. ${ }^{13,14}$

DLD is a broad diagnosis, and the group of children included is very heterogeneous. ${ }^{2,5,10-14}$ DLD can affect several areas of language and speech, ie, phonological, grammatical, semantic and/or pragmatic ability. Children with DLD may have significant difficulties in one or several linguistic domains affecting spoken language, comprehension and/or language use. ${ }^{2,5}$

In Sweden, 4-year old children with language disorder have been identified by routine language screening at the Child Health Care Center (CHC) since the 1970s. ${ }^{15}$

In 1991, the Swedish National Board of Health recommended a speech and language screening, at the age of 2.5-3 years, focusing on language as well as communication. Currently, in Gothenburg, Sweden, children aged 2.5 years are also screened for autism ${ }^{15,16}$ parallel to the language screening at the same visit at the CHC. ${ }^{16}$ This 2.5-year language and autism screening reaches almost $100 \%$ of the eligible population. ${ }^{3,15,16}$

The 2.5-year language screening consists of two parts, 1) a parental questionnaire that contains questions about the child's language development, parents' concern and oral motor difficulties and 2) a brief observation of the child's language and communication skills by an experienced nurse. ${ }^{17,18}$ There are specific guidelines available for the language screening for bilingual children. These guidelines will prevent the children screening positive due to lack of exposure to the Swedish language. ${ }^{15}$ Earlier research has shown that children identified with DLD in the language screening are at high risk of having remaining language problems at the age of 6 and 8 years, as well as problems consistent with a neuropsychiatric/ neurodevelopmental diagnosis at early school age..$^{3,11,17}$ When expressive speech and language problems become less prominent, problems in other developmental areas may become more obvious. ${ }^{11,17}$ Approximately, 5\%-6\% of the whole population screen positive in the language screening, ${ }^{17}$ of whom $\sim 1 \%$ of the children also screen positive in the autism screening. ${ }^{16}$ Children with a positive outcome in the language screening show poor vocabulary, no spoken two-word sentences and/or poor language comprehension and are referred to the Pediatric Speech and Language Pathology Clinic (PSLPC) at the Queen Silvia Children's Hospital. In the autism screening, the nurse uses the M-CHAT and makes an observation of the child's joint attention abilities. ${ }^{16}$ Those who have a positive outcome in the autism screening are referred to the Child Neuropsychiatric Clinic at the Queen Silvia Children's Hospital, both clinics situated in Gothenburg, Sweden. ${ }^{3,16}$

Comorbidity is common: according to longitudinal studies, $>60 \%$ of children with late developing language at 2.5 years of age, show problems with motor skills, intellectual disability (ID) and/or behavior when they are at school age, when examined by a multidisciplinary team. ${ }^{11,19-22}$ In one longitudinal study following children identified with language problems according to the language screening at 2.5 years, $72 \%$ had neuropsychiatric (either autism, ADHD or both) or learning disorders in addition to their persistent language disorder at the age of 7 years and a third of them also met the criteria for developmental coordination disorder. ${ }^{11}$ Thus, language development requires intact motor, cognitive and linguistic skills, and problems in any area can lead to persistent speech and language problems. ${ }^{23,24}$

However, different symptoms within speech and language, motor function, behavior, memory and learning may also vary with age. This complexity was recently studied in a 5 -year follow-up of children who screened positive for either language disorder or autism at the age of 2.5 years. ${ }^{3}$ The study focused on 237 children who were referred to, and assessed, at the PSLPC ( $\mathrm{n}=176$ language screening positive) or the Child Neuropsychiatry Clinic ( $n=61$ autism screening positive) at the Queen Silvia Children's Hospital, Gothenburg, Sweden. When the 237 children were followed up 5 years later, 96 (40\%) had established neurodevelopmental disorders or problems, often beyond DLD and autism spectrum disorder. ${ }^{3}$

It can be difficult to unravel at an early age which late talking children will be "self-correcting" and which children will go on to have persistent language problems or other neurodevelopmental problems. The current research literature suggests that the wait-and-see approach is outdated ${ }^{3,4}$ and furthermore that late bloomers may need watchful surveillance during the preschool period. ${ }^{3}$ 
Comorbidity is also common among other diagnoses, eg, ADHD is much more common with comorbidity than without, ${ }^{25}$ and children with mild ID may have serious problems in other areas of development such as perception and social skills. ${ }^{26}$ Early Symptomatic Syndromes Eliciting Neurodevelopmental Clinical Examinations (ESSENCE) ${ }^{13}$ is a concept that highlights and draws attention to the complexity and comorbidity between different neurodevelopmental problems and diagnoses present in young children. These overlapping areas are language, communication, general development, social skills, attention, behavior, mood, motor function and sleep. If the child has problems or impairments in any of these areas before the age of 5 years, he/she also has a greater risk of continued problems or potential diagnoses in the same area together with problems or potential diagnoses in any of the other areas in later age. Specific disorders such as language disorders and ADHD should therefore not be seen as separate but rather as a combination of symptoms that is largely overlapping. ${ }^{13}$ It is important that SLPs are aware of this comorbidity and have instruments to examine different developmental abilities.

A parental questionnaire can serve as such a surveillance instrument and can complete the clinical assessment and be more time-efficient than the parental interview because it can directly focus on areas that parents perceive as problematic. ${ }^{27}$

One such questionnaire, intended for children 5-15 years of age is the Five to Fifteen (FTF) ${ }^{27}$ questionnaire, which focuses on a child's development in eight different areas - motor skills, executive functions, perception, memory, language, learning, social skills and psychological problems. FTF consists of 181 statements that the child's parents respond to with three response options: "Does not apply”, "Applies sometimes/to some extent" and "Certainly applies". The response options are then scored as "0", "1" or "2". The form has been developed through a long-term collaboration between researchers and clinicians in the Nordic countries (Sweden, Norway, Denmark and Finland) and has been used in many studies. ${ }^{27}$

To the best of our knowledge, there is no broad (and detailed) validated parental questionnaire intended to cover preschool children's various developmental areas in Swedish. Therefore, we developed a 124-item "Toddler version" of the FTF - FTF-toddlers (FTF-T) - intended to be used by parents of children between the ages of 2 and 5 years. ${ }^{28}$ The FTFtoddlers was preliminarily evaluated in a Master's thesis published in 2015. ${ }^{29}$

The overall aim of the current study was to describe in detail children who screened positive in the 2.5-year language screening and negative in the autism screening performed at the same visit to the CHC. We wanted to know: 1) What types of language disorder diagnoses did screening-positive children receive according to the SLP assessment?; 2) Did parents express that their child has problems with language or any other developmental area?; and 3) How did the global impairment question in each domain relate to language disorder diagnoses?

To answer research questions 2) and 3), we used the FTF-toddlers as a complementary instrument to the SLPs' clinical assessment.

\section{Patients and methods Participants}

The parents of the first 100 (68 boys, 32 girls) children, who were referred to the PSLPC after positive 2.5-year language screening at the $\mathrm{CHC}$ during 2016, were invited to participate in this study. Another 13 families were asked but declined participation. SLPs with a long experience working with young children, and additional neuropsychiatric/ neurodevelopmental difficulties, offered assessment according to the PSLPC routine guidelines. Out of the 100 children, 49 were monolingual and 51 bilingual. A child was defined as bilingual if it had a native language other than Swedish, but simultaneously met Swedish language in preschool. Almost all children in Sweden start preschool when they are 1-year old, which means that children have been exposed to Swedish language for quite some time when the 2.5-year language screening is performed.

The bilingual children were referred from all over the city. Of them, $12(12 / 51=24 \%)$ were examined with the help of an interpreter or parent.

\section{Procedure}

All referred children were offered their first visit at the PSLPC within 3 months according to the health care guarantee. Prior to the visit, a PSLPC anamnestic questionnaire was sent home, in accordance with the clinic's usual procedure. The questionnaire asks about motor-, social- and early speech and language development (eg, canonical babbling [da, ba]) and heredity (eg, of DLD, dyslexia and neuropsychiatric disorders). In addition, a consent form was enclosed along with information about the study, its purpose and approach. Most children ( $\mathrm{n}=71)$ were assessed on one occasion, some $(\mathrm{n}=28)$ on two occasions and one child on three occasions depending on the length of time required to complete the questionnaire and the child's assessment. During the visits at the PSLPC, the SLP examined the child's language and speech development and communicative profile 
with the "gold" standard language test and material. If the child was bilingual, a thorough anamnesis regarding native language was taken to establish which language that was the first language (L1). To estimate the influence of the Swedish language, the SLP also asked questions about how long and how frequently the child had been attending Swedish preschool. The bilingual children spoke mainly Somali, English and Arabic in addition to Swedish, which according to the parents, was rated to be at the same language level as their native language. They were all assessed in both their L1 and Swedish language.

At the first visit, the SLP and the parents went through the PSLPC questionnaire with questions about family history, the child's early language development and medical history. The parents were informed about FTF-toddlers and how to complete it. In most cases, the family was offered to fill out the FTF-toddlers during the visit. They could also choose to bring the FTF-toddlers home and send it back when completed. Of the bilingual children, 12 were assessed with the help of an interpreter who also assisted the parents in completing the FTF-toddlers. The visit took $\sim 1.5$ hours, and the child assessment was performed by the SLP. The child's language status was summarized in an SLP diagnosis according to ICD-10. ${ }^{7}$ The SLP informed the family about the child's language and communicative ability and about further care and intervention.

\section{Measurements, tests and materials Language comprehension}

All children were examined with the Swedish version of the Reynell Developmental Language Scales (RDLS) III receptive $^{30}$ to get a standardized measure of language comprehension. This test contains 30 different items and a picture book. Swedish norms are available for children ages 2.6-4.5 years. ${ }^{31,32}$ The raw scores were transformed to $z$-scores and an SD at or below -1.5 , was chosen as the cutoff for receptive language disorder, corresponding to the prevalence rate of $\sim 6 \%$ of DLD. If the child was bilingual, he/she was examined in both Swedish and in the native language with help from an interpreter or parent.

\section{Expressive language}

Spontaneous speech samples were selected through "reading" a storybook Babblarna ${ }^{33}$ that invited the child to speak and to use his/her communicative skills. Next, the child played with toys, either together with the parent or with the SLP. The SLP transcribed examples of words, sentences and phonology (speech sounds) online during the assessment, using both phonological and orthographic transcription. The five longest sentences were selected in each sample, and the mean value of number of words per sentence was calculated as sentence length (SL).

A global rating was performed by the SLP who graded phonology dichotomously as acceptable (yes) or not (no). "No" was assigned when atypical phonological simplification processes were present in the child's speech.

\section{Ability to participate}

Finally, the SLP did a global qualitative rating of the child's overall ability to participate during the assessment, taking for example non-verbal communication such as eye contact, use of gestures and turn-taking ability into account. If the child did participate well throughout the visit, the participation was graded as Good. Some children were disengaged, and their participation was rated as Fluctuating. If the child did not show any interest at all in participating during the visit or participated on their own conditions, the ability was graded as Poor.

\section{ICD-I 0 diagnoses}

The SLP considered whether a child with positive language screening met the criteria for language disorder based on ICD-10. ${ }^{7}$ The main categories were an expressive language disorder no F80.1, or mixed receptive-expressive language disorder no F80.2. The children who had problems with language comprehension and production were diagnosed with mixed receptive-expressive language disorder ${ }^{7}$ from the now called mixed language disorder (MLD) group. Children with good language comprehension but who used less than two-word sentences and had atypical phonological simplification processes (not a delayed phonological ability that is expected due to the child's young age) in their speech, were diagnosed with expressive language disorder ${ }^{7}$ from the now called ELD group. Children who showed spontaneous recovery and did not meet ICD-10 language disorder criteria at the SLP assessment were defined as "late bloomers".

\section{Parental rating of developmental concern}

As a complementary assessment tool, the parental form FTF-toddlers ${ }^{28}$ was used. It is a new toddler version ${ }^{29}$ of the FTF. ${ }^{27}$ The original FTF serves as an assessment or screening tool in the investigation of various areas of development and different behavior patterns. ${ }^{27}$ It is normed and tested in several studies in different clinical populations ${ }^{26}$ and has shown good validity. ${ }^{27}$ Reliability is good, and internal consistency has proven to be high. ${ }^{23}$

The FTF-toddlers is an unpublished questionnaire that currently is tested in different clinical groups of children. 
FTF-toddlers contains eight domains; Motor, Executive functions, Perception, Memory, Language, Learning, Social skills, Child's behaviour, which are divided into eight associated subdomains. Each domain contains several statements, in total 124, concerning the child's health and overall development. These are answered on a Likert scale; 0: Does not apply, 1: Applies sometimes/to some extent or 2: Applies. Parents are also able to give the answer "not applicable", for example, when they experience that the child has not reached the level of development as expected due to their age. After completion of each domain, parents summarize if problems within this domain impact their child's everyday life in the generic "impairment question", ie, the overall parental concern within that area. These answers are graded as: 0 , No; 1 , A little; 2, A great deal; and 3, Very much. The instruction is that parents should consider their children's recent development and behavior approximately over the past 3 months. ${ }^{27}$ A mean score is then calculated for each domain. In this study, the impairment questions rated as 1-3 (ie, a little to very much) were collapsed and interpreted as "Concerns".

\section{Statistical analysis}

Since the scores deviated from the normal distribution, nonparametric statistics were used. In comparisons between two subgroups, Mann-Whitney $U$ tests was used for continuous variables and Fisher's exact test for dichotomous variables. For comparison between three unordered groups, KruskalWallis test was used for continuous variables, and chisquared test was used for dichotomous variables and ordered categorical variables. Significance level was set at $P<0.05$, two-tailed throughout. To test reliability of the statements in each FTF-toddlers domain, Cronbach's alpha was used.

\section{Ethics}

The study was approved by the Regional Ethical review Board at the University of Gothenburg, Sweden (GU-306-17).
The parents gave written informed consent prior to data collection.

\section{Results Demographics}

The mean age of the 100 children was 35 months (range 24-45 months) at the first visit. The girl:boy ratio was 1:2 in the whole group, and 20\% had not used canonical babbling according to the parents. Most children were the second child in their family. Half of the group, $50 \%$, had heredity for DLD and dyslexia, and $77 \%$ of them were boys. Eighteen percent of the children had a family history of both neuropsychiatric disorder and DLD according to the anamnestic questionnaire; this group was almost equally distributed between girls and boys. The bilingual group consisted of 22 different additional languages, mainly Somali, English and Arabic.

\section{Language outcome}

Based on the results of the language assessment and all available anamnestic information, three different subgroups were formed: MLD $(n=52), \operatorname{ELD}(n=35)$ and late bloomer $(n=13)$ (no language disorder according to the SLP assessment) (Table 1).

The MLD group consisted of children with language comprehension significantly below average, who spoke 1.5 words per utterance and one-third of them had acceptable phonology. Importantly, 45 of them were bilingual.

The ELD group consisted of children with the highest number of transient hearing loss and ear problems. These are well known factors influencing the child's speech ability and in particular phonology. In contrast to the MLD and ELD group, the late bloomers used at least three-word utterances, almost all had an acceptable phonology/speech output, and only three of them were bilingual.

As expected, due to the group criteria the MLD group scored lowest ( $z=-3.3$, range -8.14 to 3.91 ) on the RDLS III.

Table I Diagnostic groups divided by gender, medical conditions, participation ability during the SLP assessment, language ability and bilingualism

\begin{tabular}{|c|c|c|c|c|c|c|c|c|}
\hline $\begin{array}{l}\text { Language } \\
\text { groups }\end{array}$ & $\begin{array}{l}\text { Gender } \\
(\mathrm{m} / \mathrm{f})\end{array}$ & $\begin{array}{l}\text { Transient } \\
\text { hearing loss/ } \\
\text { recurrent } \\
\text { otitis }(\mathrm{m} / \mathrm{f})\end{array}$ & $\begin{array}{l}\text { Pregnancy } \\
\text { or birth } \\
\text { problems } \\
(\mathrm{m} / \mathrm{f})\end{array}$ & $\begin{array}{l}\text { Participation } \\
\text { (good/fluctuating/ } \\
\text { poor) }\end{array}$ & $\begin{array}{l}\text { RDLS, }^{a} \\
\text { z-value } \\
\text { (mean) }\end{array}$ & $\begin{array}{l}\text { Sentence, } \\
\text { length (number } \\
\text { of words per } \\
\text { utterance) } \\
\text { (mean) }\end{array}$ & $\begin{array}{l}\text { Acceptable } \\
\text { phonology } \\
\text { (yes/no) }\end{array}$ & $\begin{array}{l}\text { Bilingual } \\
(\mathrm{m} / \mathrm{f})\end{array}$ \\
\hline $\operatorname{MLD}(n=52)$ & $34 / 18$ & $3 / 0$ & $8 / 4$ & $14 / 2 \mid / 17$ & -3.3 & 1.58 & $18 / 34$ & $30 / 15$ \\
\hline $\operatorname{ELD}(n=35)$ & $24 / 11$ & $4 / 2$ & $5 / 0$ & $29 / 6 / 0$ & -0.38 & 1.74 & $5 / 30$ & $1 / 2$ \\
\hline $\begin{array}{l}\text { Late bloomer } \\
(n=13)\end{array}$ & $10 / 3$ & $\mathrm{I} / 0$ & $2 / 0$ & $1 \mathrm{I} / 2 / 0$ & -0.57 & 3.23 & $10 / 3$ & $2 / 1$ \\
\hline
\end{tabular}

Note: ${ }^{\text {I }} 2$ children from the MLD group did not participate enough to get a score at RDLS III.

Abbreviations: ELD, expressive language disorder; MLD, mixed language disorder; RDLS, Reynell Developmental Language Scales; SLP, speech and language pathologist. 
The result is based on the assessment of 40 children in the MLD group. The rest of the group, 12 children, did not participate enough to get at full result from the test. Expressive language level, measured as SL (range 0-4), was almost identical for MLD $(m=1.58)$ and $\operatorname{ELD}(m=1.74)$, while most of the late bloomers spoke in three- to four-word utterances $(m=3.23)$. In the ELD group, 14\% had an age appropriate acceptable phonology development, ie, had established sufficient number of consonants and used phonological processes typical for the current age-span, compared to $35 \%$ in the MLD group and 77\% in the late bloomer group. The child's participation during the visit varied. In the MLD group, 33\% of the children who participated were graded Poor, whereas the participation of the children in the other two groups was rated as Fluctuating or Good.

The presence of bilingualism differed between the groups. Forty-five of 52 (86\%) children in the group with MLD, 3 of $35(8 \%)$ children in the ELD group and 3 of $13(23 \%)$ late talking children were bilingual. In the MLD and ELD groups, there were about $50 \%$ more boys than girls, whereas in the late bloomer group there was $66 \%$ boys (Table 1 ).

\section{Outcome of the parental rating on the FTF-toddlers}

The Cronbach's $\alpha$ ranged from 0.55 to 0.88 , indicating acceptable reliability in the FTF domains and subdomains (Table 2). The result of the FTF-domain mean scores is presented and compared across each diagnostic language group. Bold figures represent significant group differences. There were significant differences in domain mean scores between language groups in Language comprehension, Communication and Social skills, where the MLD group had significantly more problems than the children with ELD and late bloomers, who did not differ from each other.

Parents in the MLD group generally reported more problems in their children in several domains compared to parents of children with ELD and late bloomers. They were also significantly more worried about Language comprehension and Social skills than the other parents were. Children with ELD were reported to have spoken language problems to the same degree as children with MLD. Parents of the late bloomer group reported less problems in general in the FTFtoddlers domains compared to the other two groups.

In Table 3, the result of the "global rating", i.e. the ten impairment questions, one for each domain, ranging from "little" to "quite a bit" to "very much" are presented. As shown in this table, there was a significant difference between the diagnostic groups in three out of eight domains; Gross/Fine motor skills, Memory and Language/Speech/ Communication. The test between groups showed that this difference was present when MLD and ELD were compared on Gross/Fine motor skills and on Learning, and when MLD and late bloomers are compared on Language/ Speech/Communication.

Parents' responses were scrutinized for each detailed statement regarding Language comprehension, Speech and Communication. In Table 4, responses of "applies" (a score of 2) were compared between the diagnostic groups.

Parents of children with MLD, checked "applies" to a higher degree than other parents. There was a significant

Table 2 FTF-toddlers domain and subdomain mean scores in each diagnostic group and test between groups

\begin{tabular}{|c|c|c|c|c|c|c|c|c|}
\hline \multicolumn{6}{|c|}{ FTF-toddlers domain mean scores by diagnostic groups } & \multicolumn{3}{|c|}{ Test between groups, $P$-value } \\
\hline Variable & $\begin{array}{l}\text { MLD } \\
(n=52)\end{array}$ & $\begin{array}{l}\text { ELD } \\
(n=35)\end{array}$ & $\begin{array}{l}\text { Late } \\
\text { bloomer } \\
(n=13)\end{array}$ & $P$-value ${ }^{a}$ & $\begin{array}{l}\text { Reliability } \\
\alpha \text {-level }\end{array}$ & $\begin{array}{l}\text { MLD vs } \\
\text { ELD }\end{array}$ & $\begin{array}{l}\text { MLD } \\
\text { vs late } \\
\text { bloomer }\end{array}$ & $\begin{array}{l}\text { ELD vs late } \\
\text { bloomer }\end{array}$ \\
\hline Gross motor skills & 0.21 & 0.15 & 0.26 & 0.93 & 0.82 & 0.95 & 0.71 & 0.79 \\
\hline Fine motor skills & $0.27^{b}$ & 0.27 & 0.27 & 0.75 & 0.75 & 0.47 & 0.70 & 0.91 \\
\hline Attention and concentration & 0.57 & 0.45 & 0.34 & 0.34 & 0.86 & 0.70 & 0.23 & 0.12 \\
\hline $\begin{array}{l}\text { Overactivity and } \\
\text { impulsiveness }\end{array}$ & 0.61 & 0.49 & 0.53 & 0.63 & 0.87 & 0.35 & 0.69 & 0.78 \\
\hline Passivity/inactivity & 0.25 & 0.26 & 0.15 & 0.61 & 0.70 & 0.75 & 0.48 & 0.28 \\
\hline Perception & 0.19 & 0.16 & 0.17 & 0.78 & 0.77 & 0.75 & 0.63 & 0.48 \\
\hline Memory & 0.24 & $0.19^{c}$ & 0.12 & 0.43 & 0.86 & 0.84 & 0.22 & 0.23 \\
\hline Language comprehension & 0.57 & 0.18 & 0.16 & $<0.0001$ & 0.84 & $<0.0001$ & 0.002 & 0.61 \\
\hline Spoken language & 0.82 & $0.84^{c}$ & 0.57 & 0.17 & 0.76 & 0.87 & 0.095 & 0.064 \\
\hline Communication & $0.4 I$ & 0.21 & 0.15 & 0.013 & 0.71 & 0.009 & 0.046 & 0.89 \\
\hline Learning & 0.58 & $0.39^{c}$ & 0.39 & 0.17 & 0.55 & 0.097 & 0.20 & 0.87 \\
\hline Social skills & 0.36 & 0.17 & 0.13 & 0.01 & 0.88 & 0.02 & 0.03 & 0.57 \\
\hline Overall behavior & 0.25 & 0.18 & 0.16 & 0.23 & 0.87 & 0.14 & 0.22 & 0.84 \\
\hline
\end{tabular}

Notes: ${ }^{a}$ Bold figures represents significant differences; ${ }^{b} n=50 ;{ }^{c} n=34$.

Abbreviations: ELD, expressive language disorder; FTF, Five to Fifteen; MLD, mixed language disorder. 
Table 3 Distribution of "concern" according to the ten FTF-toddlers impairment questions

\begin{tabular}{|c|c|c|c|c|c|c|c|}
\hline \multirow[b]{2}{*}{ Variable } & \multirow[b]{2}{*}{$\begin{array}{l}\text { MLD, } \\
n=52(\%)\end{array}$} & \multirow[b]{2}{*}{$\begin{array}{l}\text { ELD, } \\
n=35(\%)\end{array}$} & \multirow[b]{2}{*}{$\begin{array}{l}\text { Late } \\
\text { bloomer, } \\
\mathrm{n}=13(\%)\end{array}$} & \multirow[b]{2}{*}{$P$-value } & \multicolumn{3}{|c|}{ Test between groups, $P$-value } \\
\hline & & & & & $\begin{array}{l}\text { MLD vs } \\
\text { ELD }\end{array}$ & $\begin{array}{l}\text { MLD vs late } \\
\text { bloomer }\end{array}$ & $\begin{array}{l}\text { ELD vs late } \\
\text { bloomer }\end{array}$ \\
\hline Gross/fine motor skills ${ }^{a}$ & II (2I.6) & I (2.9) & $3(23.1)$ & $0.04 I$ & 0.024 & 1.00 & 0.11 \\
\hline Attention and concentration & $18(34.6)$ & $10(28.6)$ & $3(23.1)$ & 0.67 & 0.72 & 0.66 & 1.00 \\
\hline Over activity and impulsiveness & $19(36.5)$ & $9(25.7)$ & $3(23.1)$ & 0.45 & 0.41 & 0.57 & 1.00 \\
\hline Passivity/inactivity & $8(15.4)$ & $3(8.6)$ & I (7.7) & 0.55 & 0.55 & 0.84 & 1.00 \\
\hline Perception & $7(13.5)$ & $6(17.1)$ & $2(15.4)$ & 0.89 & 0.86 & 1.00 & 1.00 \\
\hline Memory & $12(23.1)$ & $2(5.9)$ & $0(0.0)$ & 0.024 & 0.061 & 0.10 & 1.00 \\
\hline Language, speech, communication ${ }^{a}$ & $40(76.9)$ & $25(73.5)$ & $5(38.5)$ & 0.022 & 0.91 & 0.022 & 0.060 \\
\hline Learning $^{\mathrm{a}}$ & $20(38.5)$ & $5(14.7)$ & $3(23.1)$ & 0.052 & 0.030 & 0.48 & 0.77 \\
\hline Social skills ${ }^{\mathrm{a}}$ & I8 (34.6) & $9(26.5)$ & $3(23.1)$ & 0.60 & 0.58 & 0.66 & 1.00 \\
\hline Behavior & $14(26.9)$ & 4 (II.8) & $3(23.1)$ & 0.24 & 0.15 & 1.00 & 0.58 \\
\hline
\end{tabular}

Notes: Bold figures represents significant differences. ${ }^{a} \mathrm{All}$ parents did not answer every impairment question. Abbreviations: ELD, expressive language disorder; FTF, Five to Fifteen; MLD, mixed language disorder.

difference in Language comprehension in question no 56 "Understanding statement about opposites" and in question no 60 "Has difficulty with the meaning of if - later" between the group with MLD and ELD. Parents of children with MLD and ELD were more concerned about Speech than parents of late bloomers. There were more parents in the MLD group who checked "applies" in the Speech statements than in Language comprehension statements (Table 4). There was a significant difference in the statements "Difficulty saying two-word utterances" and "Difficulty finding words" where both the MLD and ELD group had significantly more problems than late bloomers. When it comes to Communication, the parents of children with MLD reported significantly more "Difficulty with making conversation" than the other groups.

\section{Discussion}

The overall aim of the present study was to describe in detail language and overall development in 100 children who screened positive in the 2.5-year language screening, but not in the autism screening. Monolingual children as well as bilingual children were included, meaning that the group examined is probably representative of language screening positive children in Swedish "metropolitan" areas.

A main finding from this study was that the language screening at 2.5 years seems to identify children with DLD with a very high rate of accuracy, and with a reasonable proportion of false positives, only $13 \%$ were "late bloomers". Thus, the screening seems to meet the requirements stated by Wilson and Jungner; ${ }^{34}$ a primary screening should be simple to perform, easy to understand for parents, children and health professionals and produce valid results. ${ }^{34}$

The majority (87\%) of children received an ICD-10 diagnosis at the SLP assessment and more than half had problems with both receptive and expressive language. The MLD group had $z$-scores 3 SDs below the mean on RDLSIII and 12 children scored at floor level and were therefore not included in the comparison with the other two groups. The MLD also had expressive problems to the same extent as the ELD group, with an SL of one word per utterance, a result that is expected for 1-year-old children. ${ }^{35}$ However, the ELD group had more difficulty with phonology/speech sounds (86\%) than the MLD group (65\%).

Heredity for late developing language ${ }^{17}$ and/or reading difficulties/dyslexia ${ }^{12}$ was present in half of the children, and heredity for neurodevelopmental disorders (NP) and DLD was present in one of five children supporting the notion that DLD has a multifactorial origin with complex heredity patterns. ${ }^{2}$ Furthermore, the majority were boys, replicating the sex ratio of DLD of 1 girl:2 boys. ${ }^{35}$

Parents' opinion about their child's development is always important to consider. In this study, we asked the parents to complete the newly developed FTF-toddlers questionnaire. Even though the children who screened positive for autism are not included, we found that parents endorsed several problems within other developmental areas. However, compared to previously reported "comorbid" rates, $3,11,13,26$ the frequencies of such problems were not very high, except in the case of Language, Communication and Social skills.

There was a relationship between the extent of language problems documented by SLPs and parents' reported problems in the domain scores of the FTF-toddlers. Three-quarters of the parents in the MLD and ELD groups expressed problems within Language, Speech and Communication. In addition, parents of children with MLD recognized problems within Social skills. Notably, more than one-third of the late bloomer group expressed the same worries with Social skills. For instance, around $50 \%$ of them checked the items not 
Table 4 Percentage "applies" in the statements of language comprehension, speech and communication divided by diagnostic groups

\begin{tabular}{|c|c|c|c|c|c|c|c|}
\hline \multicolumn{5}{|l|}{ Statements in the Language domain } & \multicolumn{3}{|c|}{ Test between groups $P$-value } \\
\hline Variable & $\begin{array}{l}\text { MLD }(n=52) \\
(\%)\end{array}$ & $\begin{array}{l}\text { ELD } \\
(n=35)(\%)\end{array}$ & $\begin{array}{l}\text { Late } \\
\text { bloomer } \\
(n=13)(\%)\end{array}$ & $P$-value & $\begin{array}{l}\text { MLD } \\
\text { vs ELD }\end{array}$ & $\begin{array}{l}\text { MLD } \\
\text { vs late } \\
\text { bloomer }\end{array}$ & $\begin{array}{l}\text { ELD } \\
\text { vs late } \\
\text { bloomer }\end{array}$ \\
\hline \multicolumn{8}{|l|}{ Language comprehension } \\
\hline Difficulty understanding words & $6(11.5)$ & $\mathrm{I}(2.9)$ & $0(0.0)$ & 0.17 & 0.29 & 0.49 & 1.00 \\
\hline $\begin{array}{l}\text { Difficulty understanding simple } \\
\text { instructions }\end{array}$ & $5(9.6)$ & $0(0.0)$ & $0(0.0)$ & 0.088 & 0.14 & 0.63 & 1.00 \\
\hline $\begin{array}{l}\text { Difficulty with opposite words yes/no, } \\
\text { happy/sad }\end{array}$ & $5(9.6)$ & $0(0.0)$ & $0(0.0)$ & 0.088 & 0.14 & 0.63 & 1.00 \\
\hline Difficulty with terms like big/small, in/on & $14(27.5)$ & $\mathrm{I}(2.9)$ & $\mathrm{I}(8.3)$ & 0.0073 & 0.004 & 0.31 & 0.90 \\
\hline Difficulty remembering two instructions & $3(6.0)$ & $0(0.0)$ & $0(0.0)$ & 0.23 & 0.41 & 0.99 & 1.00 \\
\hline $\begin{array}{l}\text { Difficulty understanding a story read } \\
\text { aloud }\end{array}$ & $9(18.4)$ & I (3.0) & I (7.7) & 0.093 & 0.071 & 0.65 & 0.98 \\
\hline $\begin{array}{l}\text { Difficulty with the meaning of if-later } \\
\text { (eg if you eat food now, you will get } \\
\text { icecream) }\end{array}$ & $14(26.9)$ & $\mathrm{I}(2.9)$ & I (8.3) & 0.0096 & 0.006 & 0.32 & 0.92 \\
\hline \multicolumn{8}{|l|}{ Speech } \\
\hline $\begin{array}{l}\text { Difficulty saying single words and short } \\
\text { sentences }\end{array}$ & $23(46.0)$ & I8 (5।.4) & I (7.7) & 0.020 & 0.79 & 0.02 & 0.01 \\
\hline $\begin{array}{l}\text { Difficulty speaking so that parents } \\
\text { understand }\end{array}$ & $18(34.6)$ & $13(37.1)$ & $2(I 5.4)$ & 0.34 & 0.99 & 0.31 & 0.27 \\
\hline $\begin{array}{l}\text { Difficulty speaking so that unfamiliar } \\
\text { people understand }\end{array}$ & $32(6 \mid .5)$ & $25(73.5)$ & $5(38.5)$ & 0.082 & 0.36 & 0.23 & 0.060 \\
\hline Makes language sounds mistakes & $28(56.0)$ & $21(65.6)$ & $6(46.2)$ & 0.45 & 0.53 & 0.74 & 0.38 \\
\hline $\begin{array}{l}\text { Difficulty finding words or uses alternate } \\
\text { words }\end{array}$ & $19(40.4)$ & $14(46.7)$ & $\mathrm{I}(7.7)$ & 0.046 & 0.76 & 0.048 & 0.027 \\
\hline Has a hoarse voice & $2(3.9)$ & $0(0.0)$ & $0(0.0)$ & 0.39 & 0.71 & 1.00 & 1.00 \\
\hline Has a shrill voice & $5(9.6)$ & $2(5.9)$ & $\mathrm{I}(7.7)$ & 0.82 & 0.85 & 1.00 & 1.00 \\
\hline $\begin{array}{l}\text { Stutters or repeats words or part } \\
\text { of words over and over }\end{array}$ & $\mathrm{I}(2.0)$ & $\mathrm{I}(3.1)$ & $2(15.4)$ & 0.090 & 1.00 & 0.20 & 0.39 \\
\hline $\begin{array}{l}\text { Speaks so quickly it is hard to } \\
\text { comprehend }\end{array}$ & $6(12.0)$ & $0(0.0)$ & I (7.7) & 0.14 & 0.098 & 1.00 & 0.59 \\
\hline Speech very unclear/mumbles & $17(34.0)$ & $6(18.8)$ & $2(15.4)$ & 0.20 & 0.21 & 0.34 & 1.00 \\
\hline \multicolumn{8}{|l|}{ Communication } \\
\hline $\begin{array}{l}\text { Difficulty expressing what (s)he feels } \\
\text { using facial expressions }\end{array}$ & $2(3.8)$ & $\mathrm{I}(2.9)$ & $0(0.0)$ & 0.77 & 1.00 & 1.00 & 1.00 \\
\hline $\begin{array}{l}\text { Difficulty keeping to the point when }(s) \text { he } \\
\text { is telling a story }\end{array}$ & $5(13.9)$ & $2(8.0)$ & $0(0.0)$ & 0.35 & 0.78 & 0.44 & 0.90 \\
\hline $\begin{array}{l}\text { Difficulty using simple gestures to show } \\
\text { what (s)he means }\end{array}$ & $2(3.8)$ & $\mathrm{I}(2.9)$ & $0(0.0)$ & 0.77 & 1.00 & 1.00 & 1.00 \\
\hline Difficulty making conversation & $14(29.8)$ & $2(6.3)$ & $0(0.0)$ & 0.0052 & 0.02 & 0.04 & 1.00 \\
\hline
\end{tabular}

Note: Bold figures represent significant differences.

Abbreviations: ELD, expressive language disorder; MLD, mixed language disorder.

showing consideration toward other people and/or problems with following rules and/or can get completely caught up in one or few interests. Thus, late developing language can be a first sign of a more complex ESSENCE profile in late bloomers. ${ }^{3,9,11}$ When expressive language difficulties are resolved, problems with social interaction and behavior become more obvious.
The domain Social skills focuses on social relations with other people and behavior, some of which contain communicative signals. There is a clear connection between the domain Social skills and Communication (making a conversation). Regarding the domain Communication, there is a significant difference in how the parents rated their child's ability. Only one-third of the parents in the 
MLD group rated their child as having difficulty making conversation, even though the SLP found both receptive and expressive problems in all areas of speech and language. Thus, parents' expectations of their child's conversation skills may be somewhat low due to the child's limited speech output.

There was also a significant difference in concern regarding general motor skills between the MLD and ELD groups, such as difficulty in learning new motor skills. Problems with motor skills in children with language disorder have been shown in numerous previous studies. ${ }^{11,13,23}$

Parents of children with MLD expressed significantly more concerns about Language than parents of children with ELD, especially concerning the child's pragmatic ability. However, no differences between the two groups were found in the Speech domain, indicating that parents perceived their child's problem with spoken language similarly, irrespective of language comprehension level. The finding, that there are more parents who are concerned about speech than language in the MLD group, may be due to the comprehension impairment not having been detected by the parents. Children are often using non-verbal clues to help them cope in their environment, and parents have difficulties to detect that children with DLD only have "situation" understanding/comprehension - not language comprehension per se. ${ }^{35}$ In contrast, problems with speech output are more obvious and something that non-professionals/parents often worry about. The ten impairment questions, ie, the "global summary" of each domain, showed differences between the diagnostic subgroups on the FTF-toddlers in only three domains: Gross/Fine Motor Skills, Memory and Language/ Speech/Communication. The differences were found between the MLD and the ELD group in motor development, but not between ELD and "late bloomers". As expected, a significant difference in the impairment questions concerning Language/ Speech/Communication was found between MLD and the late bloomers, but not between ELD and late bloomers. There was a significant difference between the MLD and the ELD group in the impairment question Learning, which is one of the areas of concern within the concept of ESSENCE. ${ }^{13}$ This may indicate an ESSENCE profile in the MLD group, where almost $40 \%$ were rated as having Learning problems according to the FTF-toddlers and as inability to participate in the SLP assessment.

The majority (three-quarters) of the MLD children had problems with participating in the SLP assessment. Their ability to participate was impaired in different ways; for example, the child showed no interest in interaction or had a high activity level that made it hard for the child to participate. Among the children in the MLD group, 12 children could not participate in the language comprehension test. Their behavior could be symptomatic of limited language ability or problems within other developmental areas such as social skills. Half of all children in the group had heredity for DLD and $36 \%$ of them also had heredity for other neuropsychiatric disorders/ESSENCE. Therefore, it is important to assess the child's general development, with a combination of anamnestic information, language assessment and perhaps with FTF-toddlers, to identify children in need of further evaluation. This will give us a picture of possible impaired abilities - as well as relative strengths - across several developmental domains, which accords with the ESSENCE concept. ${ }^{13}$

Clinicians urgently need some way to distinguish between children presenting with early language delays who are likely to grow out of their problems and those who are likely to have persisting problems. ${ }^{4}$ Some of our late bloomers may be considered as false positives later on, but some may also present with more problems. ${ }^{3}$ Eight of the $n=35$ 2.5-year language screening positive children, who underwent at least one neuropsychiatric assessment 5 years later, had been considered to be late bloomers "only" at their first SLP assessment. ${ }^{3}$

Thus, late bloomers may also need watchful surveillance during the preschool period. ${ }^{4}$ This dataset has the potential to help address that question currently and also prospectively when we conduct the planned follow-up.

\section{Limitations}

This study was performed in a clinical setting by experienced SLPs. A possible limitation is that no inter- or intra-rate reliability measures were performed on the Phonology and SL ratings. However, the SLPs were all experienced and the assessment procedure chosen is the "Gold standard" for SLPs working with toddlers in Sweden. Another possible limitation is that there are no standard norms available for FTF-toddlers yet, therefore we presented raw scores and group differences as complementary information to the ICD-10 diagnosis. Nonetheless, concern raised in the impairment questions regarding fine- and gross motor skills, memory, language, speech and communication allow us to speculate that other neurodevelopmental ESSENCE problems may be present already at age 2.5 years.

\section{Conclusion}

The vast majority, almost nine out of ten children, identified by language screening at age 2.5 years were diagnosed with 
ICD-10 language disorder diagnoses when assessed at the PSLP clinic. Moreover, half of them were bilingual. More than half of the identified children had MLD, and a third had ELD when examined by an SLP. Only $13 \%$ had no diagnosis, representing a reasonable rate of false positive cases in the general 2.5-year language screening. The SLPs assessment showed very significant speech-language problems and a clear ESSENCE profile among more than half of the MLD and ELD. In addition, heredity for DLD or other neuropsychiatric/neurodevelopmental disorders was present, in many cases, highlighting the need to ask about possible ESSENCE problems in siblings and parents. However, only a few problems within other developmental areas were acknowledged in the FTF-toddlers questionnaire.

\section{Acknowledgments}

This study was supported by grants from the Local Research and Developmental Council and the Swedish Science Council of the VästraGötaland Region, Sweden. We wish to thank all colleagues at the Queen Silvia Children's Hospital, Department of Pediatric Speech and Language Pathology, for their help and support.

\section{Disclosure}

The authors report no conflicts of interest in this work. The authors alone are responsible for the content and writing of the paper.

\section{References}

1. Smithson L, Paradis J, Nicoladis E. Bilingualism and receptive vocabulary achievement: could sociocultural context make a difference? Biling Lang Cogn. 2014;17(04):810-821.

2. Bishop DV. What causes specific language impairment in children? Curr Dir Psychol Sci. 2006;15(5):217-221.

3. Miniscalco C, Fernell E, Thompson L, Sandberg E, Kadesjö B, Gillberg C. Development problems were common five years after positive screening for language disorders and, or, autism at 2.5 years of age. Acta Paediatr. 2018;107(10):1739-1749.

4. Capone Singleton N. Late talkers: why the wait-and-see approach is outdated. Pediatr Clin North Am. 2018;65(1):13-29.

5. Reilly S, Tomblin B, Law J, et al. Specific language impairment: a convenient label for whom? Int J Lang Commun Disord. 2014;49(4): 416-451.

6. Ebbels SH, Wright L, Brockbank S, et al. Effectiveness of 1:1 speech and language therapy for older children with (developmental) language disorder. Int J Lang Commun Disord. 2017;52(4):528-539.

7. ICD-10. Svensk version av International Statistical Classification of Diseases and Related Health Problems. 10th ed. Geneva: World Health Organization; 1997.

8. Bishop DV, Snowling MJ, Thompson PA, Greenhalgh T; CATALISE Consortium. CATALISE: a multinational and multidisciplinary Delphi consensus study. Identifying language impairments in children. PLoS One. 2016;11(7):e0158753.

9. Bishop DV, Snowling MJ, Thompson PA, Greenhalgh T; Catalise-2 Consortium. Phase 2 of CATALISE: a multinational and multidisciplinary Delphi consensus study of problems with language development: terminology. J Child Psychol Psychiatry. 2017;58(10): $1068-1080$
10. Redmond SM, Thompson HL, Goldstein S. Psycholinguistic profiling differentiates specific language impairment from typical development and from attention-deficit/hyperactivity disorder. J Speech Lang Hear Res. 2011;54(1):99-117.

11. Miniscalco C, Nygren G, Hagberg B, Kadesjö B, Gillberg C. Neuropsychiatric and neurodevelopmental outcome at age six and seven years of children who screened positive for language problems at 30 months. Dev Med Child Neurol. 2006;48:361-366.

12. Willcutt EG, Pennington BF. Psychiatric comorbidity in children and adolescents with reading disability. $J$ Child Psychol Psychiatry. 2000;41(8):1039-1048.

13. Gillberg C. The ESSENCE in child psychiatry: early symptomatic syndromes eliciting neurodevelopmental clinical examinations. Res Dev Disabil. 2010;31(6):1543-1551.

14. Stone WL, Lee EB, Ashford L, et al. Can autism be diagnosed accurately in children under 3 years? J Child Psychol Psychiatry. 1999; 40(2):219-226.

15. Barnhälsovården. Barnhälsovårdsrapport för verksamhetsår 2011. Göteborg [Annual Child Health Care Report statistics]. Arvidsson T, Holmberg L, Reuter A, Strömberg A. Annual Report for CHC statistic; Gothenburg; 2011. Swedish.

16. Nygren G. Screening and Diagnosis of Autism Spectrum Disorders [doctoral thesis]. Gothenburg: University of Gothenburg; 2012.

17. Miniscalco C. Language Impairment in Swedish Children - A Survey of 6-Year-Olds Screened for Developmental Language Disability at 2.5 and 4 Years of Age [licentiate thesis]. Gothenburg: University of Gothenburg; 2003.

18. Mattsson CM, Mårild S, Pehrsson NG. Evaluation of a languagescreening programme for 2.5-year-olds at Child Health Centres in Sweden. Acta Paediatr. 2001;90(3):339-344.

19. Fernell E, Norrelgen F, Bozkurt I, Hellberg G, Löwing K. Developmental profiles and auditory perception in 25 children attending special preschools for language-impaired children. Acta Paediatr. 2002; 91(10):1108-1115.

20. Hagberg BS, Miniscalco C, Gillberg C. Clinic attenders with autism or attention-deficit/hyperactivity disorder: cognitive profile at school age and its relationship to preschool indicators of language delay. Res Dev Disabil. 2010;31(1):1-8.

21. Mueller KL, Tomblin JB. Examining the comorbidity of language disorders and ADHD. Top Lang Disord. 2012;32(3):228-246.

22. Tager-Flusberg H. Defining language impairments in a subgroup of children with autism spectrum disorder. Sci China Life Sci. 2015; 58(10):1044-1052.

23. Wren Y, Miller LL, Peters TJ, Emond A, Roulstone S. Prevalence and predictors of persistent speech sound disorder at eight years old: findings from a population cohort study. J Speech Lang Hear Res. 2016;59(4):647-673.

24. Rice ML. Specific language impairment, nonverbal IQ, attention-deficit/ hyperactivity disorder, autism spectrum disorder, cochlear implants, bilingualism, and dialectal variants: defining the boundaries, clarifying clinical conditions, and sorting out causes. J Speech Lang Hear Res. 2016;59(1):122-132.

25. Kadesjö B, Gillberg C. The comorbidity of ADHD in the general population of Swedish school-age children. J Child Psychol Psychiatry. 2001;42(4):487-492.

26. Lindblad I, Gillberg C, Fernell E. ADHD and other associated developmental problems in children with mild mental retardation. The use of the "Five-To-Fifteen" questionnaire in a population-based sample. Res Dev Disabil. 2011;32(6):2805-2809.

27. Kadesjö B, Janols LO, Korkman M, et al. The FTF (Five to Fifteen): the development of a parent questionnaire for the assessment of ADHD and comorbid conditions. Eur Child Adolesc Psychiatry. 2004;13(Suppl 3): 31018-138827.

28. Kadesjö B, Miniscalco C, Hagberg B, Haavisto A, Gillberg C. [webpage on the Internet]. Nordiskt formulär för utredning av barns utveckling och beteende. Småbarnsversion - för barn i åldern 2 till 5 år (Parents questionnaire) [Questionnaire for evaluation of development and behavior in 2-5 year old children]. Available from: www.5-15.org/ download. Accessed December 21, 2015. 
29. Johansson S, Karlsson H. Utprövning av Fem Till Femton-formulärets småbarnsversion för utredning av barns utveckling och beteende I a ldrarna 25-40 månader [Evaluation of the Five to fifteen questionnaire - toddlers' version for assessment of development and behavior in children aged 25-40 months] [Unpublished master's thesis in Speech and Language Pathology]. Gothenburg: Gothenburg University; 2015.

30. Edwards S, Fletcher P, Garman M, Hughes A, Letts C, Sinka I. The Reynell Developmental Language Scales III. Windsor: The University of Reading Edition. NFER-NELSON. Windsor; Publishing Company Ltd; 1997.

31. Lindman M, Åström A-L. Reynell Developmental Language Scales III, Språkförståelsedelen. Normering och studie över samband mellan barns testresultat och kön respektive typ av barnomsorg [Comprehension scale. Norms and a study of the relationships between children's test results, gender and type of childcare] [Unpublished master's thesis in Speech and Language Pathology]. Umeå: Umeå University; 2000.
32. Johansson A, Nilsson E. Normering av språkförståelsedelen I Reynell Developmental Language Scales (III) för svenska barn i åldrarna 2;0-2;5 ar [Swedish norm data for the comprehension scale of RDLS III for monolingual children in the ages 2;0-2;5] [Unpublished master's thesis in Speech and Language Pathology]. Umeå: Umeå University; 2008.

33. Tisell A, Johansson A. I Babblarnas Hus [The house of Babblarna]. Stockholm: Hattenförlag; 2011.

34. Wilson JMG, Jungner G. Principles and Practice of Screening for Disease. Geneva: World Health Organization; 1968. Public health papers no. 32. Available from: http://apps.who.int/iris/bitstream/ handle/10665/37650/WHO_PHP_34.pdf? sequence=17

35. Nettelbladt U, Salameh E. Språkutveckling och språkstörning hos barn [Language development and language disorder in children]. Del 1, Fonologi, grammatik, lexikon. Lund: Studentlitteratur AB; 2007.
Neuropsychiatric Disease and Treatment

\section{Publish your work in this journal}

Neuropsychiatric Disease and Treatment is an international, peerreviewed journal of clinical therapeutics and pharmacology focusing on concise rapid reporting of clinical or pre-clinical studies on a range of neuropsychiatric and neurological disorders. This journal is indexed on PubMed Central, the 'PsycINFO' database and CAS,

\section{Dovepress}

and is the official journal of The International Neuropsychiatric Association (INA). The manuscript management system is completely online and includes a very quick and fair peer-review system, which is all easy to use. Visit http://www.dovepress.com/testimonials.php to read real quotes from published authors.

Submit your manuscript here: http://www.dovepress.com/neuropsychiatric-disease-and-treatment-journal 